\title{
Kinetic modeling of low temperature oxidation of copper nanoparticles by $\mathrm{O}_{2}$
}

\author{
Mounir MANSOUR, Loïc FAVERGEON, Michèle PIJOLAT \\ Ecole Nationale Supérieure des Mines, SPIN-EMSE, CNRS:UMR 5307, LGF, 42023 Saint-Etienne France
}

\begin{abstract}
The mechanism and kinetics of copper nanoparticles oxidation at low temperature were investigated using thermogravimetry (TGA), differential scanning calorimetry (DSC), X-Ray diffraction (XRD) and transmission electron microscopy (TEM). Isothermal and isobaric studies of the oxidation reaction were carried out at various temperatures. It was found that working under an oxygen partial pressure of $1 \mathrm{kPa}$ in the temperature range $125-145^{\circ} \mathrm{C}$ leads to reaction where nucleation of the oxide phase is in competition with its growth. The study of the dependency of the growth rate on the oxygen partial pressure under $10 \mathrm{kPa}$ has shown the adsorption of oxygen at the surface of the oxide to be the rate-determining step. A mechanism and a kinetic model have been established to interpret the experimental curves.
\end{abstract}

Keywords: copper, nanoparticle, oxidation, nucleation, growth, kinetics.

\section{Introduction}

Nowadays, the low temperature oxidation of copper is no longer only seen as a degradation phenomenon to be avoided; it can also be regarded as an innovative reaction to be exploited. The low temperature oxidation of copper nanoparticles as a new route for synthesis of hollow nanoparticles belongs to one of a new generation of reactions that are increasingly studied [1]. Hollow nanoparticles and nanotubes with interior cylindrical or spherical pores have attracted a particular attention thanks to their potential application as new functional materials in catalysis, sensors or fillers [2,3]. However, most studies deal with the characterization of the morphological changes of the particles during the processing as well as with the nature of the oxide phase being formed and the stability of the hollow structure [4]. In contrast, at our best knowledge, except the study performed by Yabouki and Tanaka [5] neither kinetic modeling nor mechanistic study of such reactions were reported up to now. On the other hand, it is worth noticing that most studies devoted to the investigation of the mechanism and kinetics of low temperature oxidation of copper were carried out using thin plates and not nanoparticles powders [6-9]. Moreover, there is no agreement between authors on the mechanism and the kinetic law. Below $300^{\circ} \mathrm{C}$, adsorption of oxygen [10], bulk 
diffusion of copper ions due to a gradient of chemical potential [11] or under the effect of an electrical field within the oxide layer [12] as well as grain boundary diffusion [11] were proposed as possible rate-determining step. Inverse logarithmic rate law [13], power rate low [7], logarithmic and parabolic rate laws [14] were reported. Yabouki and Tanaka [5] have studied the oxidation of copper nanoparticles at $150^{\circ} \mathrm{C}-300^{\circ} \mathrm{C}$ in a $20 \%$ oxygen-nitrogen atmosphere, the rate law was found to be linear in the beginning of the oxidation before turning to a parabolic one. The nature of the oxide product strongly depends of the temperature and the duration of the oxidative treatment; either $\mathrm{Cu}_{2} \mathrm{O}$ or $\mathrm{CuO}$ as well as a mixed oxide layer could be formed [7, 9, 15]. Most of the studies consider an instantaneous nucleation of the new oxide phase and assume that the reaction is governed by the growth process only. However, Lustman [16] and Khayati [17] observed sigmoidal kinetic curves thereby indicating an oxidation reaction in which both growth and nucleation processes should be considered to explain the data.

The purpose of the present work is to study the kinetics of the oxidation of copper nanospheres into hollow cuprous oxide nanospheres $\left(\mathrm{Cu}+1 / 4 \mathrm{O}_{2}=1 / 2 \mathrm{Cu}_{2} \mathrm{O}\right)$ at low temperature and pressure and to give a deeper understanding of the related mechanisms.

\section{Experimental Procedure}

\subsection{Material}

The starting material is a nano-sized powder with a purity of $99.9 \%(0.1 \%$ of $\mathrm{Ag}, \mathrm{Ca}$ and Si impurities) provided by MTI corporation. It consisted of spherical particles with a mean particle size of $45 \mathrm{~nm}$. X-ray diffraction (XRD) analysis of the powder (Siemens / Bruker D-5000, $\mathrm{Cu} \mathrm{K}$ ) revealed the presence of a native layer of cuprous oxide. Hence, it was decided to systematically operate a reduction step prior to the oxidation experiments to obtain a fresh copper surface presenting the same state for all experiments and thus a correct calculation of the extent of conversion of $\mathrm{Cu}$ into $\mathrm{Cu}_{2} \mathrm{O}$. The complete removal of cuprous oxide native layer was verified by XRD analysis of the powder just after the reduction treatment.

\section{2. Oxidation experiments}

The oxidation experiments were carried out using a symmetrical balance Setaram TAG 16. The reacting oxidative gas mixture consisted of oxygen in helium. The oxygen partial pressure was fixed thanks to mass flow controllers (Brooks B.V) and measured due to 
an oxygen sensor (Systech Instruments Série 900) installed at the outlet of the furnace. The oxygen sensor also enables the estimation of the time needed to reach the desired oxygen partial pressure since the time of injection of oxygen into the reactive gas mixture; this time was estimated equal to 3 minutes. For each experiment about $8 \mathrm{mg}$ of copper powder were loaded in a quartz crucible forming a thin bed of about $1 \mathrm{~mm}$ thick so that we can consider fast mass and heat transfer at the bed scale. Hence it is possible to consider that all particles were in the same conditions of temperature and oxygen partial pressure. After vacuum up to 1 $\mathrm{Pa}$, a reduction step was performed during 45 minutes at $200^{\circ} \mathrm{C}$ under helium-hydrogen mixture (95\%-5\%) at a flow rate equal to $2 \mathrm{~L} \mathrm{~h}^{-1}$, then the temperature was decreased to $20^{\circ} \mathrm{C}$ and vacuum was made again in order to evacuate the reductive gas mixture. After that, the sample was heated to the targeted temperature of oxidation under a flow rate of helium equal

to $4 \mathrm{~L} \mathrm{~h}^{-1}$. Oxygen was then introduced while lowering the helium flow rate to keep a total flow rate of oxidizing mixture $\left(\mathrm{He}+\mathrm{O}_{2}\right)$ equal to $2 \mathrm{~L} \mathrm{~h}^{-1}$. This procedure was used to perform all the experiments under isobaric and isothermal conditions with an oxygen partial pressure ranging from $1 \mathrm{kPa}$ to $4 \mathrm{kPa}$ and various temperatures ranging from 125 to $145^{\circ} \mathrm{C}$. In addition, in order to verify the steady-state assumption, a SETARAM TG-DSC 111 device was used to perform simultaneous calorimetry and thermogravimetry under a flow mixture of oxygen and helium $\left(2 \mathrm{~L} \mathrm{~h}^{-1}\right)$.

\section{3. Characterization of the powder}

The powder was characterized by means of a scanning electron microscope (SEM) JEOL JSM 6400; the agglomerates size distribution was evaluated by means of a laser granulometer Mastersizer 2000. The morphological changes along the reaction at the particle level were studied by transmission electron microscope (TEM) using a Philips CM 2000 apparatus; the agglomerates were first desegregated by an ultrasound treatment for 5 minutes in methanol. The nature of the oxide phase being produced by the oxidation reaction was identified by XRD analysis. The specific surface area of the powder was estimated according to the BET method (Brunauer, Emmet and Teller) by analysis of the adsorption isotherm of nitrogen at $77 \mathrm{~K}$ using a Micromeritics ASAP 2000 apparatus. 


\section{Results and discussion}

\subsection{Characterization results}

The oxidized copper powder was analyzed by XRD after various oxidation experiments conducted under diverse temperatures $\left(125-145^{\circ} \mathrm{C}\right)$ and oxygen partial pressures (1- $4 \mathrm{kPa}$ ). As shown in Figure 1 which represents the diffractograms obtained by XRD of a copper powder oxidized for $16 \mathrm{~h}$ under various temperature and oxygen partial pressure conditions, the cuprous oxide $\mathrm{Cu}_{2} \mathrm{O}$ was found to be the only oxide phase detected. Therefore, we can consider that a single reaction of oxidation of copper occurs according to (R1):

$$
\mathrm{Cu}_{(\mathrm{s})}+1 / 4 \mathrm{O}_{2(\mathrm{~g})}=1 / 2 \mathrm{Cu}_{2} \mathrm{O}_{(\mathrm{s})}
$$

The SEM observation of the copper powder just after the reduction step shows the presence of porous agglomerates (cf. Figure S1 in ESI) whose mean size was around $10 \mu \mathrm{m}$ (cf. Figure S2 in ESI). Taking into account their spherical shape, the average size of the particles that form these agglomerates was estimated from the specific surface area of the powder $\left(\mathrm{S}_{\mathrm{BET}}=5.3 \mathrm{~m}^{2} \mathrm{~g}^{-1}\right)$ according to Eq (1) where $d$ is the mean diameter of particles and $\rho$ is the density of copper $\left(8.94 \mathrm{~g} \mathrm{~cm}^{-3}\right)$ :

$$
S_{B E T}=\frac{6}{\rho_{C u} d}
$$

$d$ was found to be equal to $122 \mathrm{~nm}$ thereby indicating a sintering of particles during the reduction heat treatment. The TEM images of initial and partially oxidized copper particles $\left(140^{\circ} \mathrm{C}\right.$ and $1 \mathrm{kPa}$ of oxygen) are shown in Figure 2 . This nanoscale characterization is in favor of outward growth of the cuprous oxide since we can see the presence of hollow regions within the particles. The oxide layer forms a uniform crown around each initial spherical copper particle. The results are in agreement with the literature data concerning the outward development of cuprous oxide and the formation of hollow particles after oxidation [18,19]. Moreover Figure 2-b confirms that the diameter of most of the particles is less than $100 \mathrm{~nm}$.

\subsection{Kinetic curves}

Assuming that a steady-state is established since the beginning of the oxidation experiments, mass gain $(\Delta m)$ measured by thermogravimetry can be converted into the extent of conversion $\alpha$ according to: 
$\alpha=\frac{m-m_{0}}{\Delta m_{t h}}=\frac{\Delta m}{\Delta m_{t h}}$

where $\mathrm{m}$ is the sample mass at time $\mathrm{t}, m_{0}$ is the sample mass just after the reduction step and $\Delta m_{t h}$ is the theoretical mass gain $(12.56 \%)$ given by Eq. (3).

$\Delta m_{t h}=\frac{1}{4} \frac{m_{0} M_{O_{2}}}{M_{C u}}$

where $M_{O_{2}}$ is the molar mass of dioxygen $\left(3210^{-3} \mathrm{~kg} \mathrm{~mol}^{-1}\right)$ and $M_{C u}$ is the molar mass of copper $\left(63.5410^{-3} \mathrm{~kg} \mathrm{~mol}^{-1}\right)$.

Figures 3 present the curves of the extent of conversion versus time as well as those of reaction rate $(\mathrm{d} \alpha / \mathrm{dt})$ versus the extent of conversion for five experiments conducted at oxidation temperatures ranging from $125^{\circ} \mathrm{C}$ to $145^{\circ} \mathrm{C}$ under a constant oxygen partial pressure of $1 \mathrm{kPa}$. It can easily be concluded that temperature has an accelerator effect on oxidation. The same kinetic curves are plotted in Figure 4 for three additional experiments conducted at a constant temperature of $140^{\circ} \mathrm{C}$ with diverse fixed oxygen partial pressures $(2 \mathrm{kPa}, 3 \mathrm{kPa}$ and $4 \mathrm{kPa}$ ). One can note that, in contrary to the effect of the temperature, an increase of oxygen partial pressure does not systematically lead to an increase in the rate of reaction whatever the extent of conversion could be. It is worthwhile to mention that all the rate curves of Figures 3 and 4 present a maximum, suggesting that a continuous nucleation process occurs in parallel with the growth process of the cuprous oxide [20]. This last hypothesis will be discussed and verified below by carrying out the so-called $f(\alpha)$ test [21].

\section{Kinetic modeling}

The kinetic model is based on precise information on the mechanism and the nature of the rate-determining step when it exists, as well as on processes of nucleation and growth involved in the transformation. The morphology of the initial solid and its changes along the reaction also contribute to the development of the kinetic model which should combine the chemical and geometrical aspects of the transformation. In this study we aimed to verify first the approximations of the steady state and the existence of a rate-determining step of growth according to experimental tests described elsewhere $[22,23]$. This showed that the rate equation followed the general expression of Eq. (4): 
$\frac{d \alpha}{d t}=\phi\left(T, P\left(O_{2}\right)\right) S_{m}(t)$

where $\phi\left(T, P\left(O_{2}\right)\right)$ is the areic reactivity of growth (in mol $\mathrm{m}^{-2} \mathrm{~s}^{-1}$ ) that depends only on chemical intensive variables such as temperature and oxygen partial pressure, and $S_{m}(t)$ is the molar space function (in $\mathrm{m}^{2} \mathrm{~mol}^{-1}$ ) that depends on time and is related to the reactional zone where the rate-determining step of growth occurs. Once both assumptions were verified, the $f(\alpha)$ test was operated [21] in order to get an indication on which processes govern the kinetics (nucleation, growth or both). Then, looking for the expression of the function $\phi\left(T, P\left(O_{2}\right)\right)$, we established the elementary steps of the growth mechanism and compared to the experimental influence of the oxygen partial pressure in order to obtain the ratedetermining step of the $\mathrm{Cu}_{2} \mathrm{O}$ growth process. Finally the expression of the function $S_{m}(t)$ could be calculated and the rate law could be confronted to the experimental data.

\section{1. The kinetic model assumptions}

\section{$\underline{\text { Steady state assumption }}$}

The mass variation $(\Delta m)$ detected by the thermobalance is a measure of the extent of reaction which, by derivation versus time, gives the reaction rate. Actually, the mass gain measured for the reaction between copper and oxygen corresponds precisely to the amount of molecules reacting at the solid surface and thus the measurement of mass change versus time gives the kinetic rate of gas adsorption. In case of a steady state (in that case there would be no accumulation of intermediate species in any part of the reacting particles) the kinetic adsorption rate should be equivalent to the copper oxidation rate. If no steady state is established, thermogravimetry would not allow the measurement of the kinetic oxidation rate, and the mass gain could not be converted into the extent of conversion $\alpha$. Since the heat flux $(\mathrm{dQ} / \mathrm{dt})$ provides a measurement of the kinetic rate of oxidation, in case of a steady-state regime, there exists a relationship between the rate deduced from thermogravimetry $(\mathrm{d}(\Delta \mathrm{m}) / \mathrm{dt})$ and that given by the heat flux measurement according to Eq. (5) [22]:

$\frac{d Q}{d t}=\frac{\Delta_{r} H^{\circ}}{\sum_{j} v_{j} M_{j}} \frac{d(\Delta m)}{d t}$

where $\Delta_{r} H^{\circ}$ is the standard enthalpy variation of the reaction, $M_{j}$ and $v_{j}$ are respectively the molar mass and the algebraic stoichiometric number of the gases $j$ involved in the reaction 
balance $\left(M_{j}=M_{O_{2}}\right.$ and $v_{j}=-1 / 4$ in the present study according to reaction R1). A steady-state test was conducted at $140^{\circ} \mathrm{C}$ under oxygen partial pressures of $1 \mathrm{kPa}$ by monitoring simultaneously the thermogravimetry and the heat flux signals. In Figure 5-a are shown the heat flux and the mass gain versus time for an experiment done at $140^{\circ} \mathrm{C}$ under $1 \mathrm{kPa}$ of oxygen. The plot of the heat flux as a function of the mass gain rate for the same experiment (Figure 5-b) gave a straight line showing that Eq. (5) is followed. Therefore, one can conclude that a steady-state assumption was established. The standard enthalpy of reaction obtained from the slope was found to be equal to $-81 \mathrm{~kJ} \mathrm{~mol}^{-1}$, which is close to that obtained by calculations based on the thermodynamic properties of copper, cuprous oxide and oxygen given by Thermodata database $\left(-85 \mathrm{~kJ} \mathrm{~mol}^{-1}\right)[24]$.

\section{Assumption on the expression of the kinetic rate equation}

Taking into account that the amount of cuprous oxide produced by nucleation can be neglected besides that due to its growth, as well as the fact that steady-state condition is verified, if in addition the growth process is controlled by one of the elementary steps of the growth mechanism, then the rate of reaction can be expressed according to Eq. (4) [25]. In order to validate the rate-determining step assumption and thus the expression given by Eq. (4), we used the so-called " $\phi S_{m}$ test" [23]; it consists of an experiment started at a temperature $T_{b}$ (for a given oxygen partial pressure $P_{b}$ ), then followed by a sudden temperature jump from $T_{b}$ to $T_{a}$ done at a given extent of conversion $\alpha_{j}$. The jump must be as fast as possible in order to neglect the variation in $S_{m}(t)$ from $T_{b}$ to $T_{a}$. Applying Eq. (4) to the rates before and after the jump, noted $r_{b}$ and $r_{a}$, respectively, one obtains:

$$
\frac{r_{a}}{r_{b}}=\frac{\phi\left(T_{a}, P_{b}\right)}{\phi\left(T_{b}, P_{b}\right)}
$$

Such an experiment can be repeated at various $\alpha_{j}$ values, and the ratios $r_{d} / r_{b}$ measured in the whole range of $\alpha$. If the ratios of $r_{a} / r_{b}$ are found to take the same value whatever $\alpha_{j}$ could be, then it can be concluded that the step controlling the kinetic rate is the same along the whole transformation. The usual kinetic models are based on the steady-state and rate determining step assumptions, however these are rarely verified, although various reasons can be at the origin of deviations such as transport limitations, parallel reactions, cracks, etc .... Figure 6 presents the result of a $\phi S_{m}$ test that was performed under an oxygen partial pressure of $1 \mathrm{kPa}$ with jumps in temperature from $130^{\circ} \mathrm{C}$ to $140^{\circ} \mathrm{C}$ (heating rate of $10^{\circ} \mathrm{C} \mathrm{min}^{-1}$ ). We 
can clearly notice that for $\alpha_{j}$ less than 0.7 the ratio $r_{a} / r_{b}$ is almost constant $(1.76 \pm 0.15)$ while for $\alpha_{j}$ above 0.7 the ratio is no longer constant and continuously decreases. Therefore, we can conclude that the reaction admits a rate-determining step of growth and Eq. (4) is valid until an extent of conversion around 0.7.

\section{"One process" or "two processes" model: $f(\alpha)$ test}

As mentioned above, the reaction involves two main processes: the nucleation of $\mathrm{Cu}_{2} \mathrm{O}$ at the surface of the copper particles and its growth. Surface nucleation obviously is considered instead of bulk nucleation since the reaction under study is a gas-solid reaction and it is not possible for the nuclei to appear inside the particle. From a general point of view, two families of models may be distinguished [25]: the "one process models" when one of the both processes is so fast compared to the second one that it can be considered as instantaneous; the "two processes models" correspond to continuous surface nucleation and growth along the reaction. It is possible to decide which kind of model has to be chosen thanks to the " $f(\alpha)$ test" already described in [21].

When surface nucleation or growth is instantaneous, $S_{m}$ does not depend on the "history" of the reaction, particularly on the temperature and partial pressures profiles before reaching a given extent of conversion, i.e. the knowledge of $\alpha$ determines that of $S_{m}$. In case of two processes models, it is necessary to take into consideration the rate at which the nuclei appear at the surface which may strongly depend on temperature and partial pressure. Consequently $S_{m}(t)$ depends on the temperature and pressure conditions in which nuclei have appeared before starting growth, and cannot be estimated from the knowledge of the extent of conversion $\alpha$ and the temperature and partial pressure at this value of $\alpha$. [21]. In other words, $S_{m}(t)$ may be written using a function of $\alpha$ in the case of the one process models, whereas it cannot in the case of the two processes models. Here Avrami-Erofeev type laws must be discarded for interpreting the experimental data due to surface nucleation and small size of the particles.

In Figure 7 the solid line represents the oxidation rate versus the extent of conversion at $140^{\circ} \mathrm{C}$ ( $1 \mathrm{kPa}$ of oxygen), whereas the dotted line describes the oxidation rate for a second experiment carried out first under the same oxygen partial pressure at $130^{\circ} \mathrm{C}$ up to $\alpha$ around 0.1 , then was done a jump in temperature (indicated by a star) from $130^{\circ} \mathrm{C}$ to $140^{\circ} \mathrm{C}$, so that the conditions returned to the same temperature and partial pressure than in the first 
experiment. After the jump (region II) the areic reactivity of growth $\phi(T, P)$ takes the same value for both experiments since it only depends on temperature and oxygen partial pressure. Therefore, according to Eq. (4) if $S_{m}(t)$ can also be expressed by a function of $\alpha$ (one process model), both curves should be superimposed in region (II); we can clearly see that this is not the case. As a result, we can assert that the kinetics of the reaction followed a two processes model. Moreover, the fact that the rate passes through a maximum as $\alpha$ increases is also in favor of a nucleation and growth process model. Consequently, the calculation of the $S_{m}(t)$ function was done considering the kinetics of appearance of the nuclei and that of their growth.

\subsection{Identification of the rate-determining step of growth and the expression of $\phi\left(T, P\left(O_{2}\right)\right)$}

The identification of the rate-determining step of growth was based on the study of the effect of the oxygen partial pressure on the kinetic rate, more precisely on the areic reactivity of growth $\phi$. We assumed that singly ionized copper vacancies and electron holes are the predominant charged defects [26] involved in the mechanism of growth, in agreement with an outward growth of $\mathrm{Cu}_{2} \mathrm{O}$. The growth mechanism consists of five elementary steps where " $s$ " represents an adsorption site and the subscripts "(ext)”, “(int)”, and “(metal)” denote the localization of species at the external gas-oxide interface, internal metal-oxide interface, and in the metal lattice, respectively:

1) Dissociative adsorption of the oxygen at the cuprous oxide surface.

$$
O_{2}+2 s \Leftrightarrow 2 s-O
$$

2) Creation of a building unit of $\mathrm{Cu}_{2} \mathrm{O}$ at the gas-oxide interface:

$$
s-O \Leftrightarrow\left(O_{O}\right)_{o x}+2\left(V_{C u}^{\prime}\right)_{o x, e x t}+2\left(h^{\circ}\right)_{o x, e x t}+s
$$

3) Diffusion of copper vacancies from the outer gas-oxide interface to the inner metaloxide interface (and related electron holes and copper ions diffusion fluxes to ensure electronegativity and material transport, respectively): 


$$
\left\{\begin{array}{l}
\left(V_{C u}^{\prime}\right)_{o x, e x t} \rightarrow\left(V_{C u}^{\prime}\right)_{o x, \mathrm{int}} \\
\left(h^{\circ}\right)_{o x, e x t} \rightarrow\left(h^{\circ}\right)_{o x, \mathrm{int}} \\
\left(C u_{C u}\right)_{o x, \mathrm{int}} \rightarrow\left(C u_{C u}^{\prime}\right)_{o x, e x t}
\end{array}\right.
$$

4) Consumption of the diffusing defects and creation of metallic neutral vacancies at the inner metal oxide interface:

$$
\left(C u_{C u}\right)_{m e t a l}+\left(V_{C u}^{\prime}\right)_{o x, \text { int }}+\left(h^{\circ}\right)_{o x, \text { int }} \Leftrightarrow\left(C u_{C u}\right)_{o x, \text { int }}+\left(V_{C u}\right)_{\text {metal }}
$$

5) Annihilation of metallic neutral vacancies in the copper lattice:

$$
\left(V_{C u}\right)_{\text {metal }} \rightarrow \varnothing
$$

The various zones are represented in Figure 8 which schematically describes a partially oxidized copper particle. A linear combination of all these steps leads to the overall reaction balance $\mathrm{R} 1$.

It is worth noticing that the outer gas-oxide interface is mobile since it progresses outwards from the initial oxide surface during the transformation while the oxide/metal interface remains at the same place. In addition, as far as the oxide layer thickness increases, voids are formed inside the initial particle due to the annihilation of copper vacancies according to step E5. Considering each of the elementary steps as a possible determining-rate step, while the other steps are at equilibrium, it is possible to calculate the corresponding theoretical expression $\phi_{i}\left(k_{i}, K_{j}, P(o 2)\right)$ where $k_{i}$ is the kinetic constant of step $i$ ( $D_{i}$ for a diffusion step) and $K_{j}$ are the equilibrium constants of the other steps $j \neq i$. In Appendix A are given the details of the calculation of $\phi_{1}$ (i. e. if the rate-determining step is the dissociative adsorption of oxygen molecules). The expressions of $\phi$ for E1 to E5 are reported in Table 1. It can be seen that the areic reactivity of growth depends of the oxygen partial pressure, so it was interesting to use the jump method to obtain directly the experimental variations of $\phi$ with $P\left(\mathrm{O}_{2}\right)$ at a given temperature.

Five oxidation experiments were carried out at $140^{\circ} \mathrm{C}$. Every experiment was performed under an oxygen partial pressure $P_{0}$ of $1 \mathrm{kPa}$ up to an extent of conversion around 
0.1 , and then a jump in oxygen partial pressure was done from $P_{0}$ to a targeted pressure $P_{i}\left(P_{i}\right.$ $=3,5,6,7$ and $8 \mathrm{kPa})$. The ratios of the rate measured after the jump $r\left(P_{i}\right)$ to the one measured before the jump $r\left(P_{1}\right)$ were thus obtained and according to Eq.(6), they provide the experimental variations in $\phi$ with the oxygen partial pressure. Figure 9 shows the experimental data for $\phi\left(P_{i}\right) / \phi\left(P_{0}\right)$ vs $P_{i}$. The data can be fitted with a straight line showing that the reactivity of growth varies linearly with the oxygen partial pressure. Looking at the various calculated expressions of $\phi$ listed in Table 1, it appears that the adsorption step E1 can be considered as the rate-determining step (at $140^{\circ} \mathrm{C}$ and in the oxygen partial pressure range $1 \mathrm{kPa}-8 \mathrm{kPa})$.

\section{2. Kinetic model and expression of $S_{m}(t)$ function}

From the previous sections, it can be settled that: (i) a steady state was established along the course of the reaction, (ii) the rate equation may be decomposed in the product of two terms $\phi\left(T, P\left(\mathrm{O}_{2}\right)\right.$ and $\mathrm{S}_{\mathrm{m}}(\mathrm{t})$, (iii) the calculation of $\mathrm{S}_{\mathrm{m}}(\mathrm{t})$ must involve the kinetics of both nucleation and growth processes, (iv) the rate-determining step of growth is the oxygen adsorption at the $\mathrm{Cu}_{2} \mathrm{O}$ surface, In addition, it was shown due to the $\phi S_{m}$ test that for $\alpha>0.7$, the conclusions (ii) to (iv) are no more valid.

First, in order to calculate $S_{m}(t)$, geometrical considerations were done as regards to the spherical shape of the particles and the outward growth of the oxide phase as previously discussed. Moreover, the continuous layer of cuprous oxide that recovers the initial copper particles (cf. Figure 2) can be considered as an argument in favor of "anisotropic" growth. This means that the first oxide nucleus appearing at the copper surface develops tangentially to the surface with a very high speed compared to its radial growth. So at the very beginning of the transformation of a given particle, it was assumed that an ultrathin oxide layer of $\mathrm{Cu}_{2} \mathrm{O}$ was present around the particle surface before its expansion due to outward radial growth. Since the nuclei were appearing at different dates during the time elapsed from 0 to $t$, the particles in the powder started to be oxidized at different dates $t$ comprised between 0 and $t$. Figure 10 represents a schematic view at time t of an ensemble of particles in the powder: not yet transformed $(a, b)$, just nucleated $(c)$, partially transformed $(d, e)$ and totally transformed (f).

Then it was necessary to take into account the nucleation kinetics through the areic frequency of nucleation $\gamma\left(T, P\left(O_{2}\right)\right)$ which is the number of nuclei appearing at the copper 
surface per meter square and per second. Its value was assumed to only depend on temperature and oxygen partial pressure. In fact, the nucleation process is known to be very sensitive to the presence of defects at the solid surface (crystallographic defects, point defects, adsorbed species, impurities, etc ...). It was previously shown from the study of the dehydration of $\mathrm{Li}_{2} \mathrm{SO}_{4}, \mathrm{H}_{2} \mathrm{O}$ single crystals, whose nucleation frequency $\gamma$ took quite different values even when they were placed in same temperature and water vapor pressure conditions [27]. The reason was precisely a great variability of the surface defects, however from a statistical point of view, due to a huge number of particles in a powder sample, the assumption of a nucleation frequency $\gamma$ representative of the nucleation kinetics was found to be acceptable [28].

Concerning the kinetics of $\mathrm{Cu}_{2} \mathrm{O}$ growth, once a nucleus appeared at time $\tau$ at the surface of the particles, the rate at which this particle will be transformed is proportional to its external surface area, noted $s_{\text {ext }}(t, \tau)$, since the rate-determining step of growth was found to be an adsorption step. The expression of $s_{\text {ext }}(t, \tau)$ could be obtained from geometrical considerations and the detailed calculations are presented in Appendix B. Thus for a nucleus appeared at time $\tau$ :

$$
s_{e x t}(t, \tau)=4 \pi r_{0}^{2}\left[1+\frac{\phi z V_{m C u}}{r_{0}}(t-\tau)\right]^{2}
$$

where $r_{0}$ is the initial radius of the particles, $z$ is the expansion factor known as the Pilling and Bedworth ratio $\left(z=V_{m C u 2 O} / 2 V_{m C u}\right.$ with $V_{m C u 2 O}$ and $V_{m C u}$ : molar volume of $\mathrm{Cu}_{2} \mathrm{O}$ and $\mathrm{Cu}$, respectively).

For the whole powder, we considered the previously published general equation of $d \alpha / d t$ according to (8) [25]:

$$
\frac{d \alpha}{d t}=\frac{\gamma \phi}{n_{0}} \int_{0}^{t} S_{L}(\tau) s_{e x t}(t, \tau) d \tau
$$


where $n_{0}$ is the initial amount of copper (moles) and $S_{L}(\tau)$ is the amount in surface areas of all the particles not yet nucleated at time $\tau<\mathrm{t}$ (cf. Figure 10). According to [23], the expression of $S_{L}(\tau)$ is given by Eq. (9):

$S_{L}=S_{L, 0} \exp \left(-\gamma S_{0} \tau\right)$

where $S_{L, O}$ is the initial amount of particles surface areas in the whole powder sample and $s_{O}$ is the initial surface of a single particle.

Finally from Equations. (7), (8) and (9), Eq. (10) could be obtained for the expression of the rate

$\frac{d \alpha}{d t}=12 \pi r_{0} \gamma \phi V_{m, C u} \int_{0}^{t}\left(1+\frac{\phi z V_{m, C u}}{r_{0}}(t-\tau)\right)^{2} \exp \left(-4 \pi r_{0}^{2} \gamma \tau\right) d \tau$

Equation (10) holds as far as t remains lower than the time required to transform one particle, noted $t_{f}$, which is given according to [20] by:

$t_{f}=\frac{r_{0}}{\phi V_{m, C u} z}\left[(z+1)^{1 / 3}-1\right]$

In fact, when $t>t_{f}$ it is necessary to take into account only the particles being under transformation and to suppress (in a mathematical way) the contribution of the particles already transformed (for which the mathematical value of the rate is not null), which can be traduced by:

$\frac{d \alpha}{d t}=12 \pi r_{0} \gamma \phi V_{m, C u} \int_{t-t_{f}}^{t}\left(1+\frac{\phi z V_{m, C u}}{r_{0}}(t-\tau)\right)^{2} \exp \left(-4 \pi r_{0}^{2} \gamma \tau\right) d \tau$

Integrating equations (10) and (12), the corresponding extent of conversion $\alpha$ could be obtained as a function of time.

The confrontation of the kinetic model to the experimental data obtained under an oxygen partial pressure of $1 \mathrm{kPa}$ is shown in Figure 11-a. The experimental $\alpha(t)$ curves for $145^{\circ} \mathrm{C}, 140^{\circ} \mathrm{C}$ and $135^{\circ} \mathrm{C}$ (dotted lines) are superimposed to the calculated ones (solid lines) up to an extent of conversion around 0.65 . Then the experimental rate of oxidation was found 
to be systematically lower than the calculated rate. Indeed, this deviation is not surprising since for $\alpha$ values ranging above 0.7 , the $\phi S_{m}$ test showed that the oxidation kinetics was no more controlled by the same regime than before. Most probably, the slowdown of the reaction was the result of an additional resistance due to the diffusion of gaseous oxygen inside the porosity of the copper agglomerates. Effectively, because of the volumic expansion of the particles due to their outward growth and the value of the expansion factor ( $z$ is equal to 1.67), the accessibility of the oxygen molecules to the inner particles was decreasing while the extent of conversion increased. The same behavior has been seen in the case of $\mathrm{CO}_{2}$ capture by calcium oxide according to: $\mathrm{CaO}_{(\mathrm{s})}+\mathrm{CO}_{2(\mathrm{~g})}=\mathrm{CaCO}_{3(\mathrm{~s})}$ [29]. For the two experiments performed at $130^{\circ} \mathrm{C}$ and $125^{\circ} \mathrm{C}$ the kinetic model is valid for $\alpha$ values ranging below the extent of conversion corresponding to the slowdown of the reaction $(\alpha=0.52$ and $\alpha=0.35)$. However, these two latter values of $\alpha$ are not close to the one predicted by the $\phi S_{m}$ test ( $\alpha=$ 0.7). This can be explained by the fact that the $\phi S_{m}$ test is performed with temperature jumps from $130^{\circ} \mathrm{C}$ to $140^{\circ} \mathrm{C}$. It must have given a different value of the extent of conversion corresponding to the change of the kinetic regime if it was performed with temperature jumps from $120^{\circ} \mathrm{C}$ to $130^{\circ} \mathrm{C}$. This explanation is also valid for the comparison of the calculated curves to the experimental ones obtained under various oxygen partial pressures at $140^{\circ} \mathrm{C}$ (Figure 11-b). The parameters of the model equations are given in Table 2.

The model fit to the experimental curves before the slowdown of the reaction provides the values of $\phi$ and $\gamma$ corresponding to each oxidation experiment. As shown in Figures 16, these two kinetic functions vary linearly versus oxygen partial pressure. For $\phi$, a such oxygen dependency is in agreement with the assumption of a dissociative adsorption of oxygen molecules as a rate determining step of the growth process and, hence, it gives an additional validation of the kinetic model before the slowing down of the reaction.

This interpretation of the kinetic data will be deeply investigated in future work by enlarging the kinetic model to the agglomerate scale by taking into account the gaseous transfer phenomena through the porosity. 


\section{Conclusion}

A detailed study of the oxidation of copper nanoparticles into cuprous oxide $\mathrm{Cu}_{2} \mathrm{O}$ was done at low temperatures $\left(125-145^{\circ} \mathrm{C}\right)$ and low oxygen partial pressures $(1-8 \mathrm{kPa})$. The experimental data were analyzed using experimental tests to help in the kinetic modeling assumptions, such as those related to the steady-state, the expression of the rate equation, the nucleation and growth processes. Moreover, it could be shown that up to an extent of conversion around 0.7 , the rate-determining step of growth was the dissociative adsorption of oxygen molecules at the surface of the oxide layer which recovers the copper particles and that the development of this oxide was outwards. Then a kinetic model involving simultaneous nucleation and anisotropic growth was established and the expression of the extent of conversion was successfully confronted to the kinetic data up to $\alpha$ corresponding to the slowdown of the reaction which was attributed to the diffusion of gaseous molecules through the porosity of the nanoparticles agglomerates. 
References:

[1] R. Nakamura, G. Matsubayashi, H. Tsuchiya, S. Fujimoto, H. Nakajima, Formation of oxide nanotubes via oxidation of $\mathrm{Fe}, \mathrm{Cu}$ and $\mathrm{Ni}$ nanowires and their structural stability: Difference in formation and shrinkage behavior of interior pores, Acta Mater. 57 (2009) 5046-5052.

[2] H.J. Fan, U. Gösele, M. Zacharias, Formation of Nanotubes and Hollow Nanoparticles Based on Kirkendall and Diffusion Processes: A Review, Small. 3 (2007) 1660-1671.

[3] N.D. Hoa, N. Van Quy, H. Jung, D. Kim, H. Kim, S.K. Hong, Synthesis of porous CuO nanowires and its application to hydrogen detection, Sensors Actuators B Chem. 146 (2010) 266-272.

[4] R. Nakamura, D. Tokozakura, J.G. Lee, H. Mori, H. Nakajima, Shrinking of hollow $\mathrm{Cu} 2 \mathrm{O}$ and $\mathrm{NiO}$ nanoparticles at high temperatures, Acta Mater. 56 (2008) 5276-5284.

[5] A. Yabuki and S. Tanaka, Oxidation behavior of copper nanoparticles at low temperature, Mater. Res. Bull, 46 (2011) 2323-2327.

[6] V. Figueiredo, E. Elangovan, G. Gonçalves, P. Barquinha, L. Pereira, N. Franco, E. Alves, R. Martins, E. Fortunato, Effect of post-annealing on the properties of copper oxide thin films obtained from the oxidation of evaporated metallic copper, Appl. Surf. Sci. 254 (2008) 3949-3954.

[7] M. Ramirez, L. Henneken, S. Virtanen, Oxidation kinetics of thin copper films and wetting behaviour of copper and Organic Solderability Preservatives (OSP) with leadfree solder, Appl. Surf. Sci. 257 (2011) 6481-6488.

[8] N.A. M. Shanid and M.A. Khadar, Evolution of nanostructure, phase transition and band gap tailoring in oxidized $\mathrm{Cu}$ thin films, Thin Solid Films. 516 (2008) 6245-6252.

[9] K.V. Rajani, S. Daniels, E. McGlynn, R.P. Gandhiraman, R. Groarke, P.J. McNally, Low temperature growth technique for nanocrystalline cuprous oxide thin films using microwave plasma oxidation of copper, Mater Lett. 71 (2012) 160-163.

[10] P.T. Landsberg, On the logarithmic rate law in chemisorption and oxidation, J. Chem. Phys. 23 (1955) 1079-1087.

[11] P.K. Kofstad, Nonstoichiometry, Diffusion and Electrical Conductivity in Binary Metal Oxides. John Wiley \& Sons Inc, 1972.

[12] N. Cabrera and N. F. Mott, Theory of the oxidation of metals, Rep. Pog. Phys. 12 (1949) 163.

[13] C. Zhong, Y. Jiang, D. Sun, J. Gong, B. Deng, S. Cao, J. Li, Oxidation kinetics of Nanosclae Copper Thin Films at Low Temperature: Characterized by Sheet Resistance and optical Transmittance, Chin. J. Phys. 47 (2009) 253-260.

[14] E.P. Surovoi and N.V. Borisova, Thermal Transformations in Nanosized Copper Layers, Russ. J. Phys. Chem. 84 (2010) 255-260.

[15] J. Liang, N. Kishi, T. Soga, T. Jimbo, Cross-sectional characterization of cupric oxide nanowires grown by thermal oxidation of copper foils, Appl. Surf. Sci. 257 (2010) 6266.

[16] B. Lustman and R.F. Mehl, Low-temperature oxidation of single crystals of copper, AIME TRANS. 143 (1941) 246-267.

[17] G.R. Khayati, E. Nourafkan, G. Karimi, J. Moradgholi, Synthesis of cuprous oxide nanoparticles by mechanochemical oxidation of copper in high planetary energy ball mill, Adv. Powder Technol. 24 (2013) 301-305.

[18] Y. Yin, R.M. Rioux, C.K. Erdonmez, S. Hughes, G.A. Somorjai, A.P. Alivisatos, Formation of Hollow Nanocrystals Through the Nanoscale Kirkendall Effect, Science. 304 (2004) 711-714. 
[19] C.J. Love, J.D. Smith, Y. Cui, K.K. Varanasi, Size-dependent thermal oxidation of copper: single-step synthesis of hierarchical nanostructures, Nanoscale, 3 (2001) 49724976.

[20] M. Soustelle, Handbook of heterogeneous Kinetics. Wiley, London, 2010.

[21] M. Pijolat and M. Soustelle, Experimental tests to validate the rate-limiting step assumption used in the kinetic analysis of solid-state reactions, Thermochim. Acta. 478 (2008) 34-40.

[22] M. Soustelle and M. Pijolat, Experimental methods useful in the kinetic modelling of heterogeneous reactions, Solid State Ionics. 95 (1997) 33-40.

[23] M. Pijolat, F. Valdivieso, M. Soustelle, Experimental test to validate the rate equation " $\mathrm{d} \alpha / \mathrm{dt}=\mathrm{kf}(\alpha)$ " used in the kinetic analysis of solid state reactions, Thermochim. Acta. 439 (2005) 86-93.

[24] THERMODATA-INPG-CNRS. Thermochemical data bank COACH, Thermodata, 38402, St. Martin d'Héres.

[25] M. Pijolat, L. Favergeon, M. Soustelle, From the drawbacks of the Arrhenius-f( $\alpha)$ rate equation towards a more general formalism and new models for the kinetic analysis of solid-gas reactions, Thermochim. Acta. 525 (2011) 93-102.

[26] R. Haugsrud, P. Kofstad, On the oxygen pressure dependence of high temperature oxidation of copper, Mat. Sci. 254 (1997) 65-72.

[27] L. Favergeon, Etude de la germination en surface dans les transformations chimiques des solides. Cas de la déshydratation du sulfate de lithium monohydraté, Thesis, SaintEtienne, France, 2006.

[28] L. Favergeon, M. Pijolat, F. Valdivieso, C. Helbert, Experimental study and MonteCarlo simulation of the nucleation and growth processes during the dehydration of $\mathrm{Li}_{2} \mathrm{SO}_{4} \cdot \mathrm{H}_{2} \mathrm{O}$ single crystals, Phys. Chem. Chem. Phys. 7 (2005) 3723-3727.

[29] L. Rouchon, Etude cinétique expérimentale et modélisation de la reaction de carbonatation de l'oxyde de calcium, Thesis, Saint-Etienne, France, 2012. 


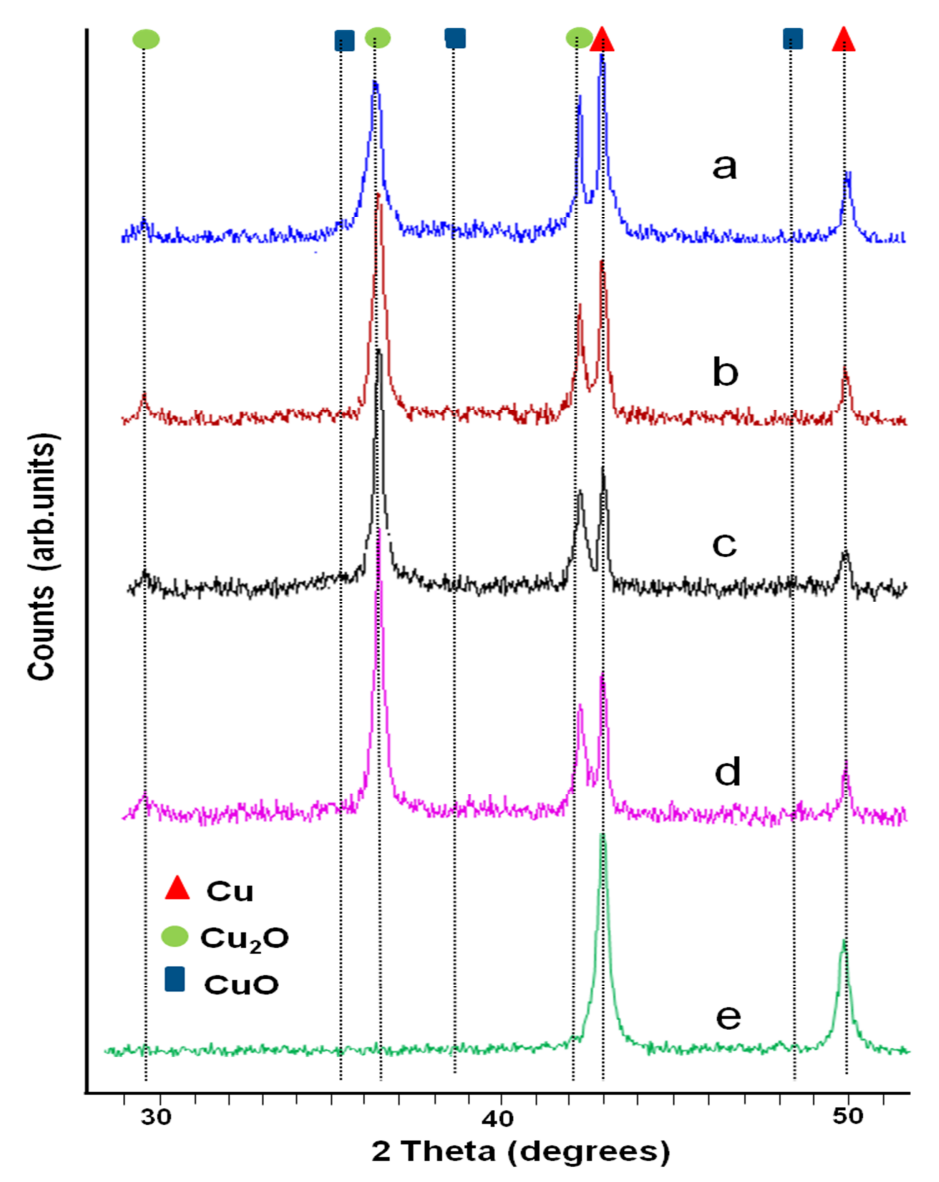

Fig 1: X-ray diffraction patterns of the powder after oxidation for $16 \mathrm{~h}$ at: a) $\mathrm{T}=125^{\circ} \mathrm{C}, \mathrm{P}\left(\mathrm{O}_{2}\right)$ $=1 \mathrm{kPa}$; b) $\mathrm{T}=125^{\circ} \mathrm{C}, \mathrm{P}\left(\mathrm{O}_{2}\right)=4 \mathrm{kPa}$; $) \mathrm{T}=145^{\circ} \mathrm{C}, \mathrm{P}\left(\mathrm{O}_{2}\right)=1 \mathrm{kPa}$; d $) \mathrm{T}=145^{\circ} \mathrm{C}, \mathrm{P}\left(\mathrm{O}_{2}\right)=4$ $\mathrm{kPa} ; \mathrm{e})$ powder just after reduction heat treatment.
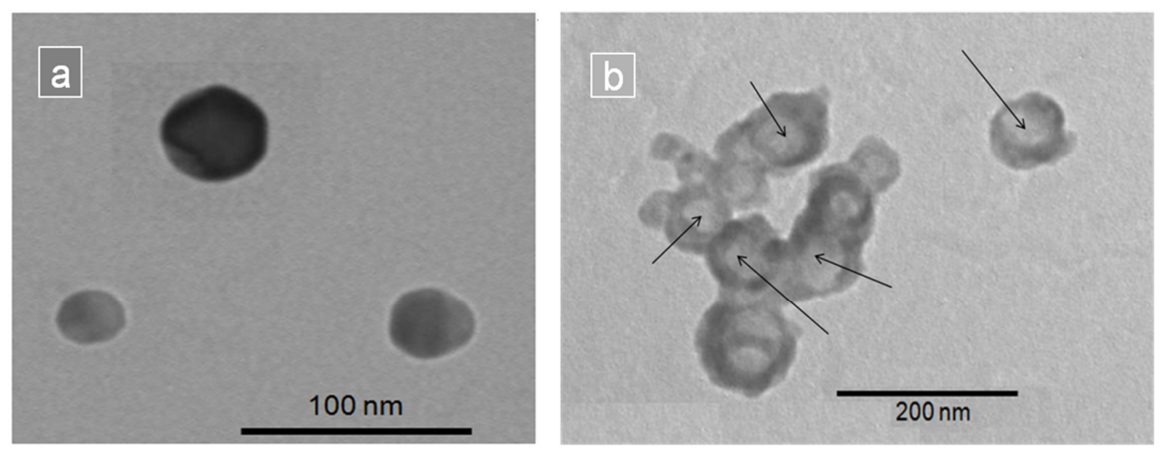

Fig 2: TEM images a) starting copper particles; b) partially oxidized copper particles after $2 \mathrm{~h}$ of oxidation treatement $\left(\mathrm{T}=140^{\circ} \mathrm{C}, \mathrm{P}\left(\mathrm{O}_{2}\right)=1 \mathrm{kPa}\right)$. 

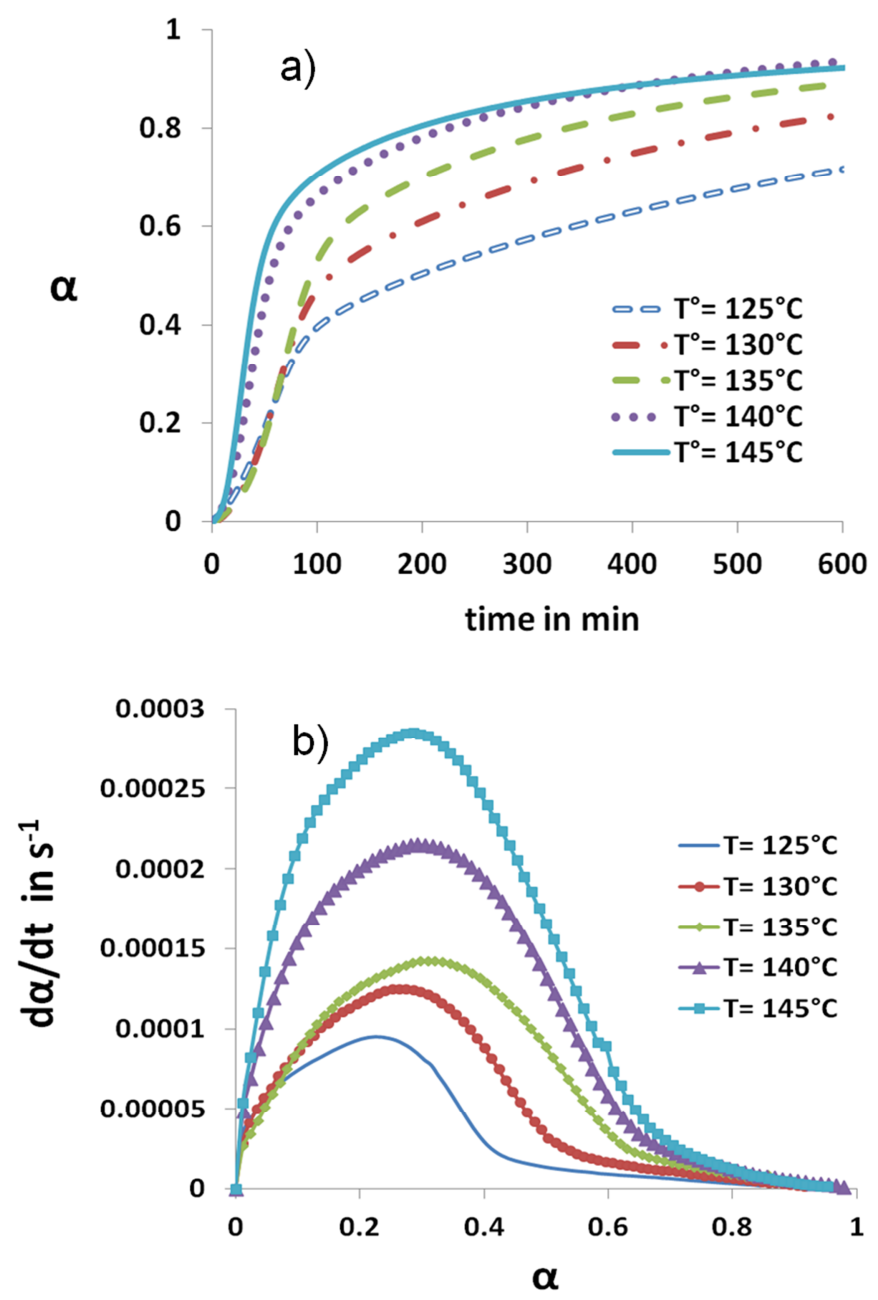

Fig 3: Isothermal kinetic curves of copper oxidation under an oxygen partial pressure of $1 \mathrm{kPa}$ : a) $\alpha(\mathrm{t})$ curves; b) reaction rate curves : d $\alpha / \mathrm{dt}$ versus $\alpha$. 

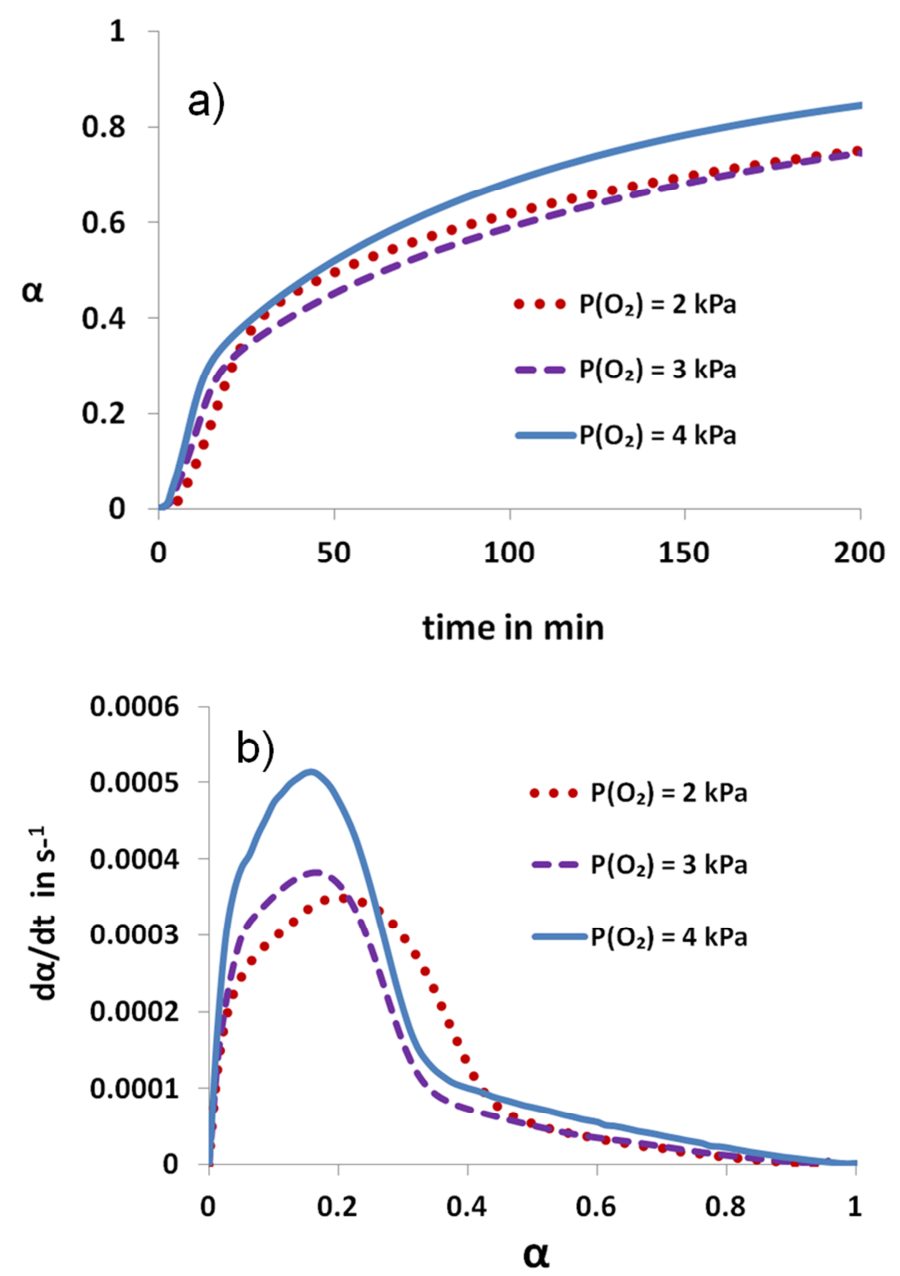

Fig 4: Isobaric kinetic curves of copper oxidation at $140^{\circ} \mathrm{C}$ :

a) $\alpha(t)$ curves; b) reaction rate curves : d $\alpha / d t$ versus $\alpha$. 

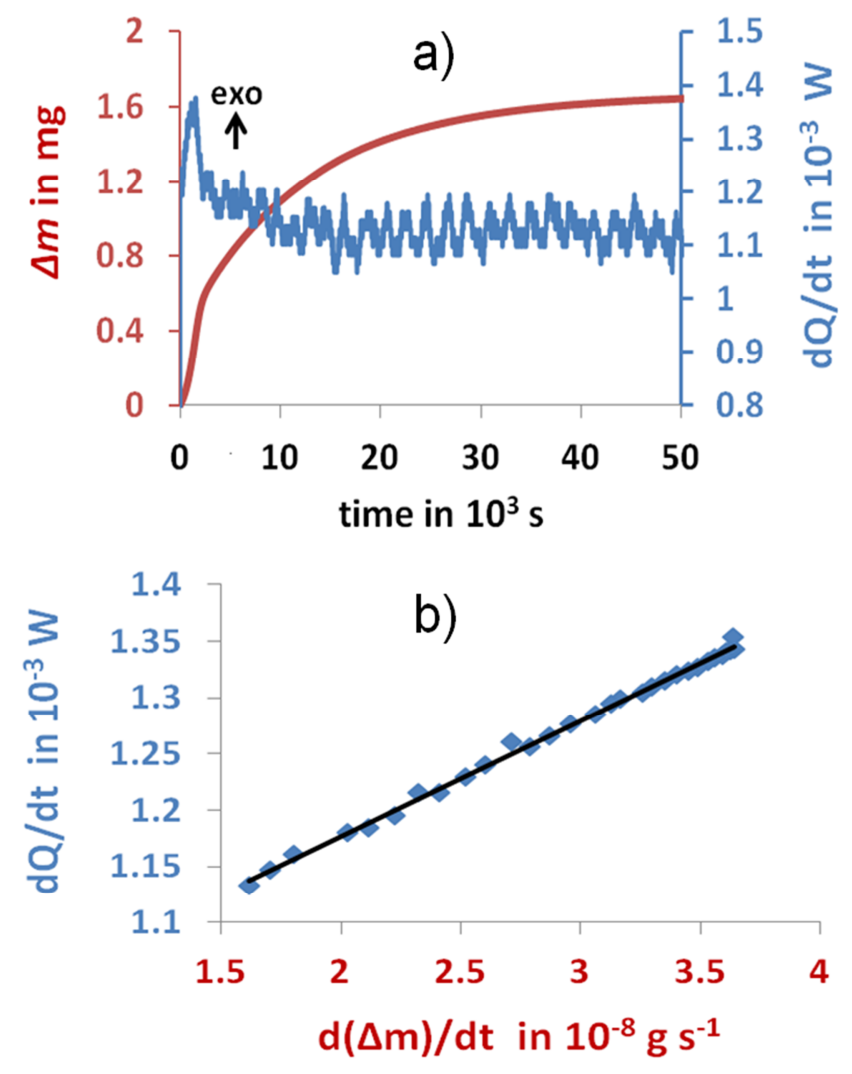

Fig 5: Steady-state test: $\mathrm{P}\left(\mathrm{O}_{2}\right)=1 \mathrm{kPa}, \mathrm{T}=140^{\circ} \mathrm{C}$

a) heat flux and mass gain versus time; b) heat flux as a function of mass gain rate

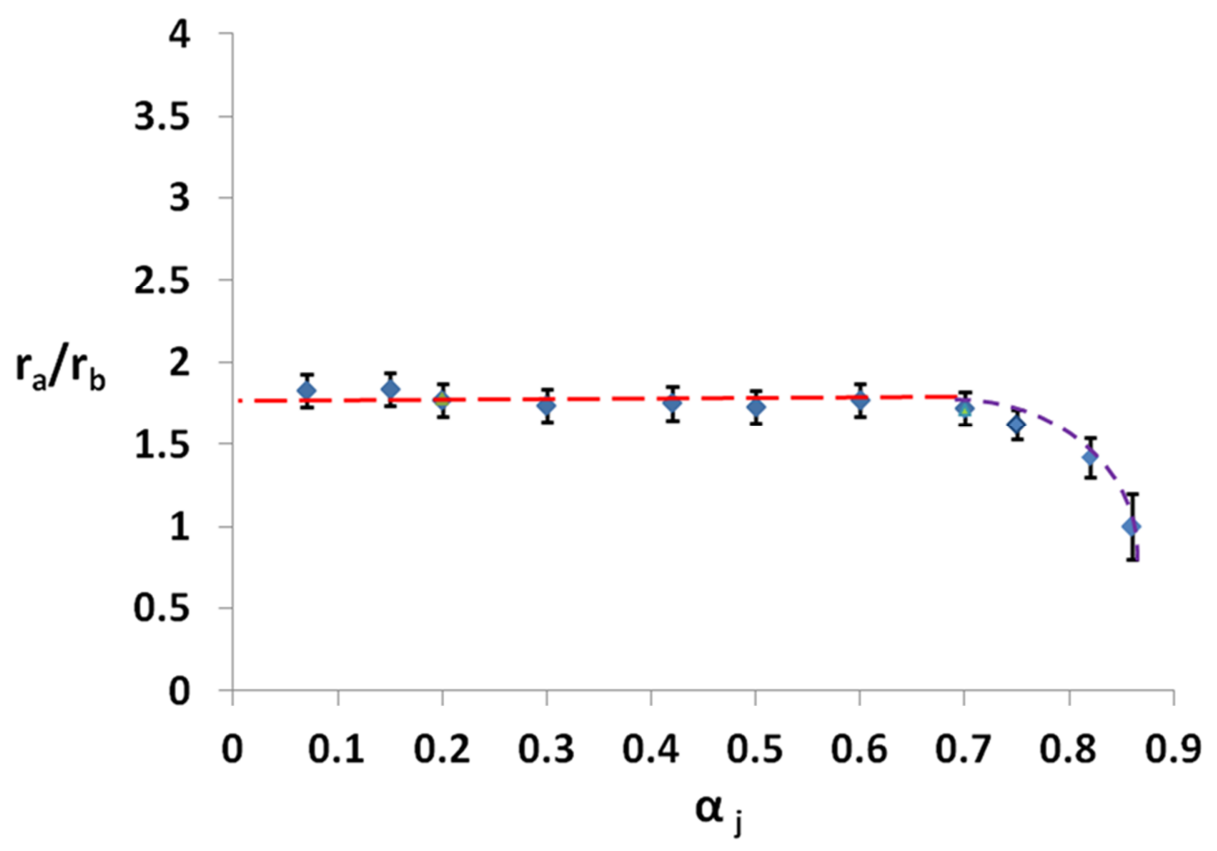

Fig 6: $\phi S_{m}$ test; $\mathrm{P}\left(\mathrm{O}_{2}\right)=1 \mathrm{kPa}, \mathrm{T}=140^{\circ} \mathrm{C}$. 


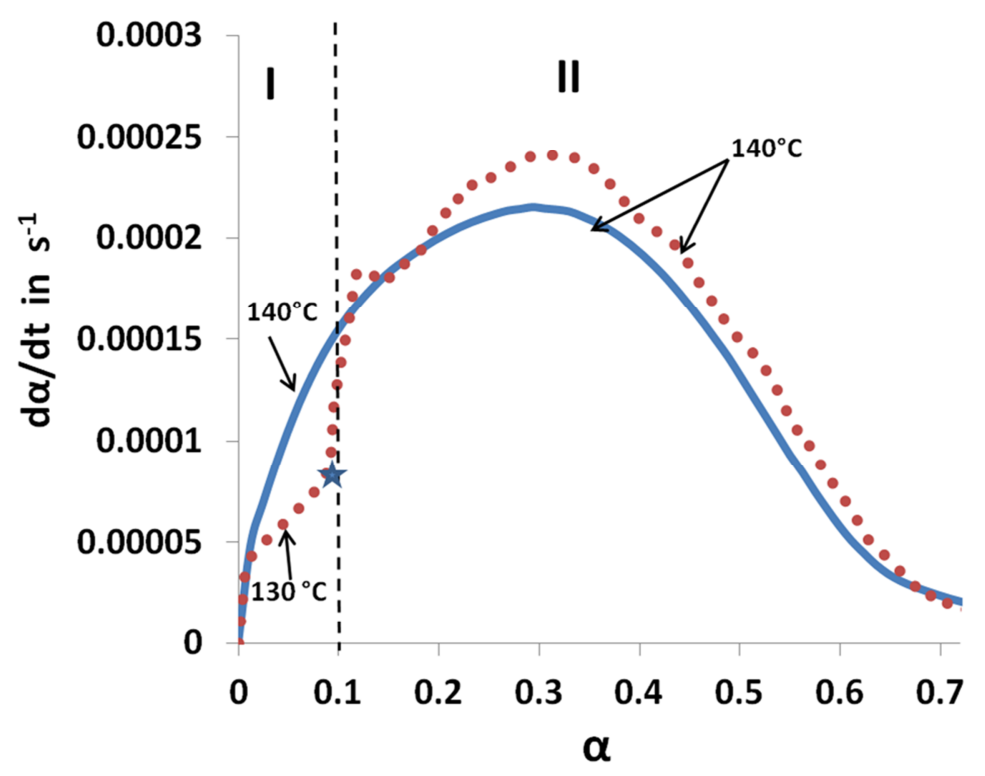

Fig 7: Rate curves for $f(\alpha)$ test.

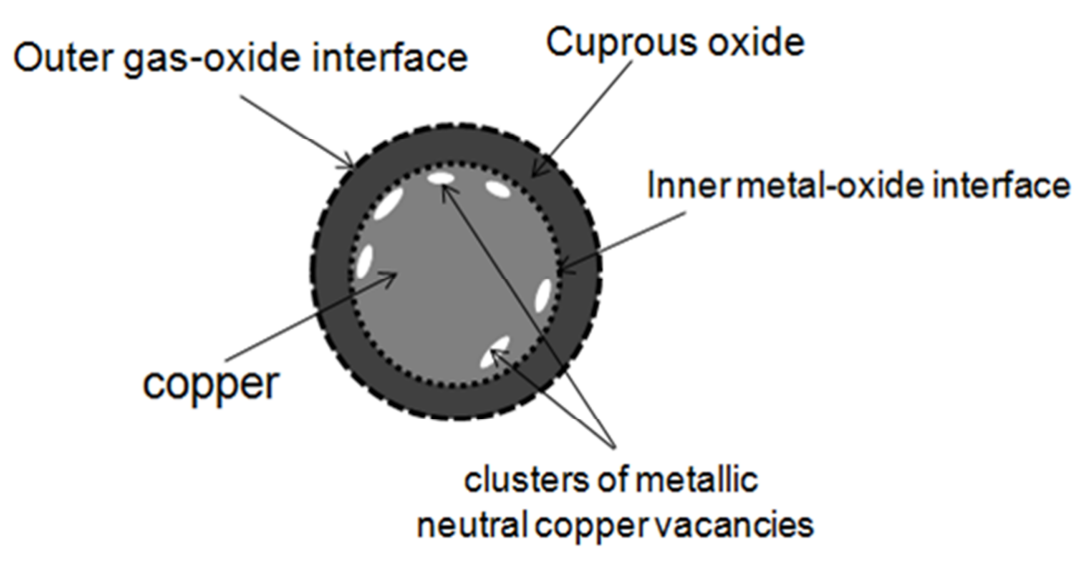

Fig 8: Scheme of a partially oxidized copper particle. 


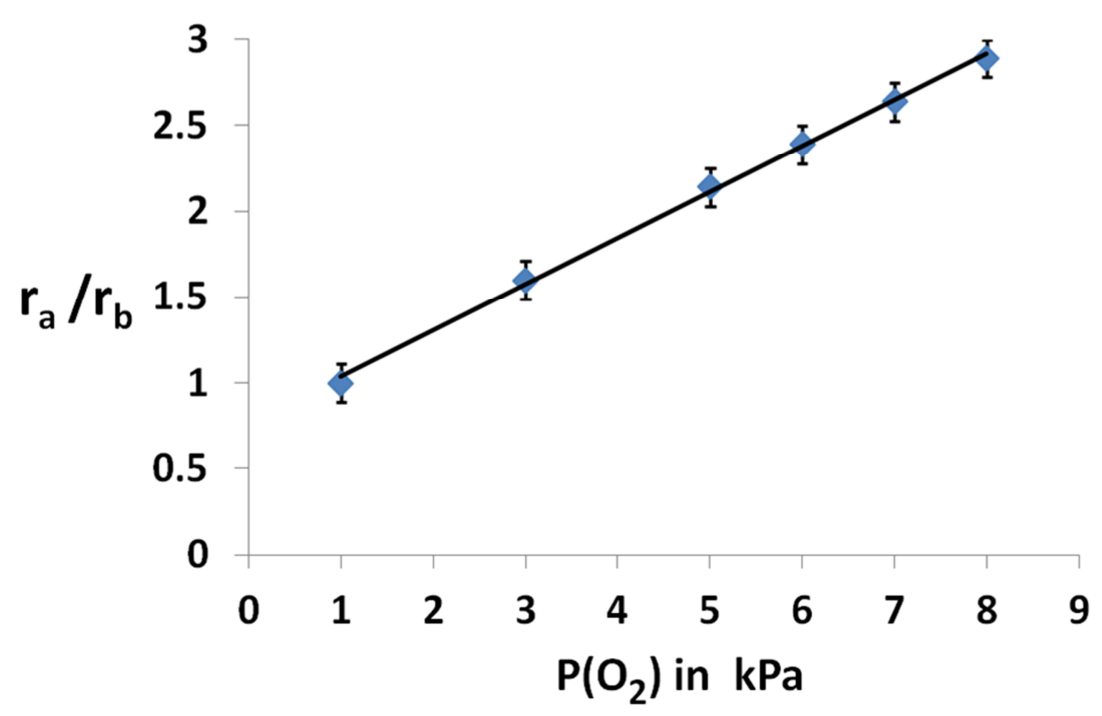

Fig 9: $\mathrm{r}_{\mathrm{a}} / \mathrm{r}_{\mathrm{b}}$ versus $\mathrm{P}\left(\mathrm{O}_{2}\right)$.

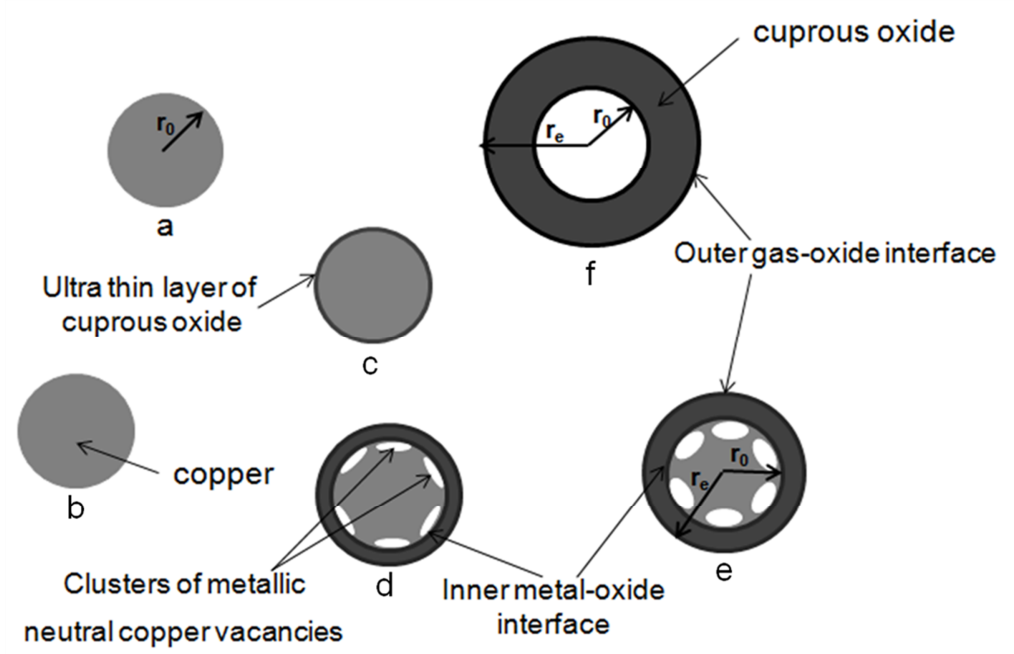

Fig 10: A picture of a population

of particles reacting according to the assumptions verified below at a given time $(\mathrm{t})$ during oxidation. 

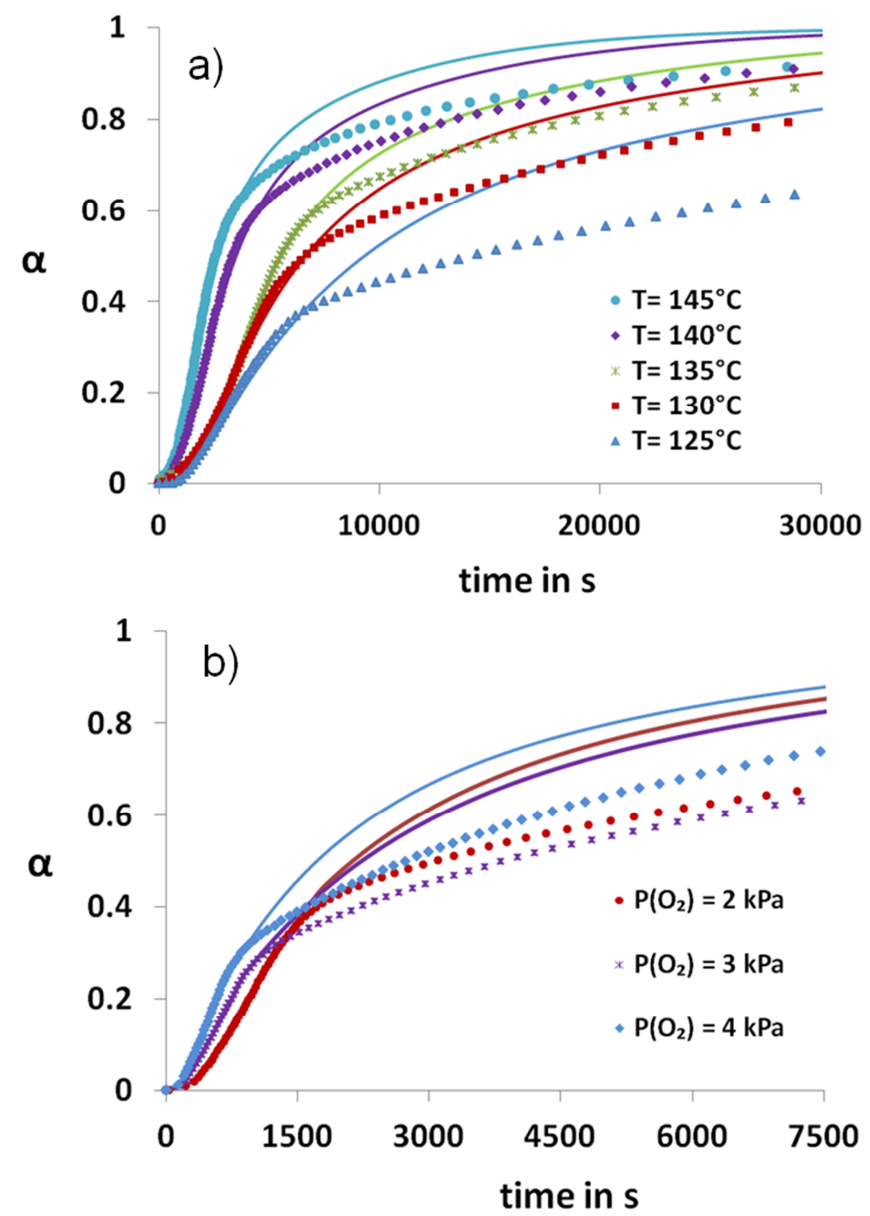

Fig 11: Comparison between experimental and calculated kinetic curves; a) $\mathrm{P}\left(\mathrm{O}_{2}\right)=1 \mathrm{kPa}$; $\mathrm{b}$ ) $\mathrm{T}=140^{\circ} \mathrm{C}$ (lines: kinetic model; symbols: experimental data). 

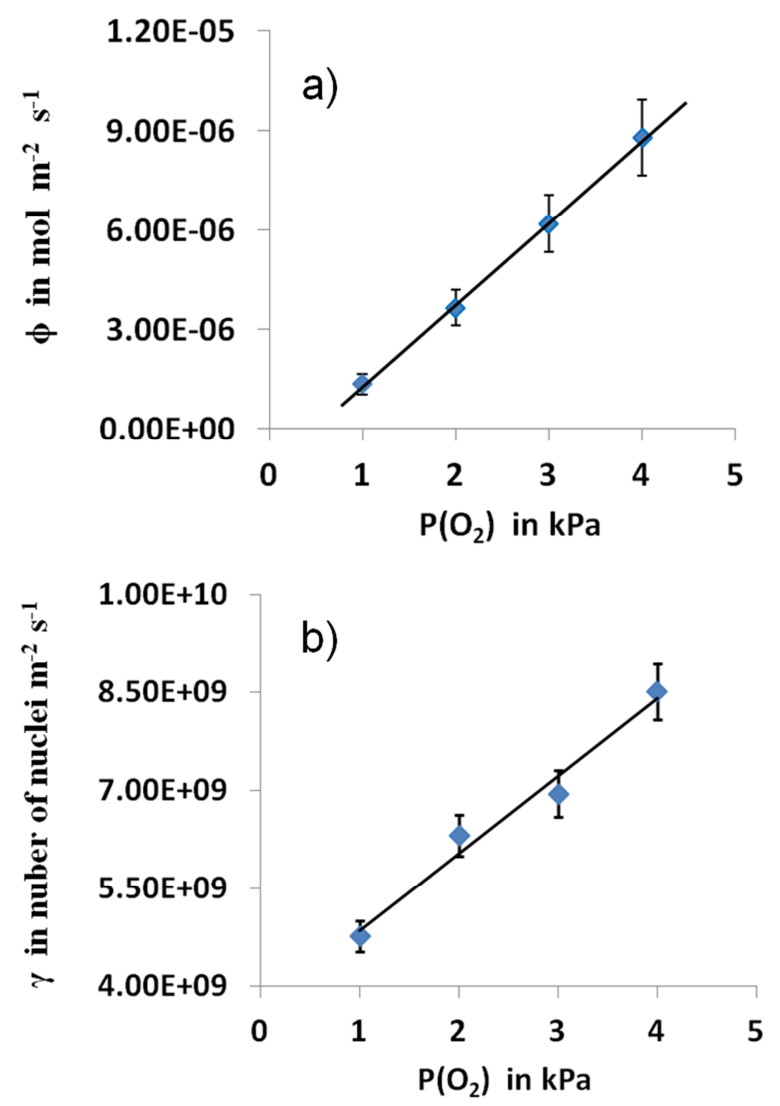

Fig 12: Variation of the calculated $\phi(a)$ and $\gamma(b)$ values versus oxygen partial pressure. 


\begin{tabular}{|c|c|}
\hline $\begin{array}{c}\text { Rate determining } \\
\text { step (i) }\end{array}$ & Areic reactivity of growth $\phi_{\mathrm{i}}$ \\
\hline 1$)$ & $\phi_{1}=k_{1}\left(\frac{K_{4}^{2} K_{5}^{2} K_{2}}{1+K_{4}^{2} K_{5}^{2} K_{2}}\right)^{2} P_{O_{2}}$ \\
\hline 2$)$ & $\phi_{2}=k_{2}\left(\frac{K_{1}^{1 / 2} P_{O_{2}}^{1 / 2}}{1+K_{1}^{1 / 2} P_{O_{2}}^{1 / 2}}\right)$ \\
\hline 3$)$ & $\phi_{3}=\frac{D_{V_{C u}}}{l_{0}} \cdot K_{2}^{1 / 4} K_{1}^{1 / 8} P_{O_{2}}^{1 / 8}$ \\
\hline 4$)$ & $\phi_{4}=k_{4} K_{1}^{1 / 4} K_{2}^{1 / 2} P_{O_{2}}^{1 / 4}$ \\
\hline 5$)$ & $\phi_{5}=k_{5} K_{4} K_{1}^{1 / 4} K_{2}^{1 / 2} P_{O_{2}}^{1 / 4}$ \\
\hline
\end{tabular}

Table 1: Calculated expressions of the areic reactivity of growth: $\phi\left(\mathrm{k}_{\mathrm{i}}, \mathrm{K}_{\mathrm{j}}, \mathrm{P}(\mathrm{o} 2)\right)$ where $\mathrm{k}_{\mathrm{i}}, \mathrm{K}_{\mathrm{j}}$, $\mathrm{D}_{\mathrm{V}^{\prime} \mathrm{Cu}}$ and $\mathrm{l}_{0}$ are the kinetic constant of the determining-rate step (i), the equilibrium constants of the other elementary steps ( $\mathrm{j}$ ), the diffusion constant of the singly ionized copper vacancies through the oxide lattice, $l_{0}$ an arbitrary length equal to $1 \mathrm{~m}$ in the S.I units.

\begin{tabular}{|c|c|c|c|c|c|}
\hline \multirow{2}{*}{\multicolumn{2}{|c|}{ Physical constants }} & \multicolumn{4}{|c|}{ Kinetic constants } \\
\hline & & $T$ in $K$ & $\mathrm{P}(\mathrm{O})$ in $\mathrm{kPa}$ & in $m o l m^{-2}$ & \\
\hline $\mathrm{r}_{0}$ in $\mathrm{m}$ & $\mathrm{Z}$ & 398 & \multirow{5}{*}{1} & $(2.33 \pm 0.30) 10^{-7}$ & (1.76 \\
\hline $6110^{-9}$ & 1.67 & 403 & & $(8.30 \pm 1.10) 10^{-7}$ & $(2.67 \pm 0.13) 10^{9}$ \\
\hline $\mathrm{M}_{\mathrm{Cu}}$ in $\mathrm{kg} \mathrm{mol}^{-1}$ & $\mathrm{M}_{\mathrm{O} 2}$ in $\mathrm{kg} \mathrm{mol}^{-1}$ & 408 & & $(8.57 \pm 1.20) 10^{-7}$ & $(2.88 \pm 0.14) 10^{9}$ \\
\hline 0.063 & 0.032 & 413 & & $(1.35 \pm 0.10) 10^{-6}$ & $(4.77 \pm 0.23) 10^{9}$ \\
\hline $\mathrm{V}_{\mathrm{m}, \mathrm{Cu}}$ in $\mathrm{m}^{3} \mathrm{~mol}^{-1}$ & $\mathrm{~V}_{\mathrm{m}, \mathrm{Cu} 2 \mathrm{O}}$ in $\mathrm{m}^{3} \mathrm{~mol}^{-1}$ & 418 & & $(1.90 \pm 0.20) 10^{-6}$ & $(6.16 \pm 0.30) 10^{9}$ \\
\hline $7.1210^{-6}$ & $2.3810^{-5}$ & \multirow{3}{*}{413} & 2 & $(3.66 \pm 0.50) 10^{-6}$ & $(6.31 \pm 0.31) 10^{9}$ \\
\hline$v_{\mathrm{O} 2}$ & $\rho_{\mathrm{Cu}}$ in $\mathrm{g} \mathrm{cm}^{-3}$ & & 3 & $(6.20 \pm 0.80) 10^{-6}$ & $(6.80 \pm 0.34) 10^{9}$ \\
\hline$-1 / 4$ & 8.94 & & 4 & $(8.80 \pm 1.20) 10^{-6}$ & $(8.50 \pm 0.42) 10^{9}$ \\
\hline
\end{tabular}

Table 2: Physical and kinetic constants involved in the calculation of the kinetic curves (the values of $\phi$ and $\gamma$ are adjusted parameters)

Appendix A. Calculation of the areic reactivity of growth $\left(\phi_{1}\right)$ in the case of a dissociative adsorption of oxygen molecules as the rate determining step of the growth process. 
Notations:

$\theta_{s} \quad$ the fraction of free adsorption sites

$\theta_{s-o} \quad$ the fraction of occupied adsorption sites

$k_{i}, k_{-i}$ the rate constants of the elementary steps $\mathrm{E}_{\mathrm{i}}$ and $\mathrm{E}_{-\mathrm{i}}$ (reverse elementary step) respectively

$K_{i} \quad$ the equilibrium constant of the elementary step $(i)$

Calculation of $\phi_{1}$ :

Considering the elementary step E1 as the rate determining step, the areic reactivity of growth is given by:

$\phi_{1}=k_{1} \theta_{s}^{2} P_{O_{2}}-k_{-1} \theta_{s-O}^{2}=k_{1} \theta_{s}^{2} P_{O_{2}}\left(1-\frac{k_{-1} \theta_{s-O}^{2}}{k_{1} \theta_{s}^{2} P_{O_{2}}}\right)$

Since $K_{1}=k_{1} / k_{-1}$ :

$\phi_{1}=k_{1} \theta_{s}^{2} P_{O_{2}}\left(1-\frac{\theta_{s-O}^{2}}{K_{1} \theta_{s}^{2} P_{O_{2}}}\right)$

From the expression of the equilibrium constant of the elementary step (E2) we obtain:

$\frac{\theta_{s-O}}{\theta_{s}}=\frac{\left[\left(h^{\circ}\right)_{o x, e x t}\right]^{2}\left[\left(V_{C u}^{\prime}\right)_{o x, e x t}\right]^{2}}{K_{2}}$

From the expressions of the equilibrium constants of the 4th and the 5th elementary steps (E4, E5):

$\left[\left(V_{C u}^{\prime}\right)_{o x, e x t}\right]^{2}\left[\left(h^{\circ}\right)_{o x, e x t}\right]^{2}=\frac{1}{K_{4}^{2} K_{5}^{2}}$

From Eq. (A.1.3) and Eq. (A.1.4) we obtain:

$\frac{\theta_{s-O}^{2}}{\theta_{s}^{2}}=\frac{1}{K_{4}^{4} K_{5}^{4} K_{2}^{2}}$

Combining the tow equations (A.1.5) and (A.1.2) leads to: 
$\phi_{1}=k_{1} \theta_{s}^{2} P_{O_{2}}\left(1-\frac{1}{K_{1} K_{4}^{4} K_{5}^{4} K_{2}^{2} P_{O_{2}}}\right)$

Assuming the conservation of the number of adsorption sites $\left(\theta_{s-o}+\theta_{s}=1\right)$ we obtain from Eq. (A.1.5):

$\theta_{s}^{2}=\left(\frac{K_{4}^{2} K_{5}^{2} K_{2}}{1+K_{4}^{2} K_{5}^{2} K_{2}}\right)^{2}$

And thus:

$\phi_{1}=k_{1}\left(\frac{K_{4}^{2} K_{5}^{2} K_{2}}{1+K_{4}^{2} K_{5}^{2} K_{2}}\right)^{2} P_{O_{2}}\left(1-\frac{1}{K_{1} K_{2}^{2} K_{4}^{4} K_{5}^{4} P_{O_{2}}}\right)$

Moreover, the equilibrium constant of the overall reaction balance (R1) can be written as:

$$
K_{G}=\frac{1}{P_{O_{2}, E q}^{1 / 4}}=K_{1}^{1 / 4} K_{2}^{1 / 2} K_{4} K_{5}
$$

This gives:

$P_{O_{2}, E q}^{1 / 4}=\frac{1}{K_{1}^{1 / 4} K_{2}^{1 / 2} K_{4} K_{5}}$

And then:

$\phi_{1}=k_{1}\left(\frac{K_{4}^{2} K_{5}^{2} K_{2}}{1+K_{4}^{2} K_{5}^{2} K_{2}}\right)^{2} P_{O_{2}}\left(1-\left(\frac{P_{o_{2}, E q}}{P_{o_{2}}}\right)\right)$

Based on Thermodata [24] database, calculation of the equilibrium oxygen partial pressure for temperatures equal to $125^{\circ} \mathrm{C}$ and $145^{\circ} \mathrm{C}$ gave $1.10^{-28} \mathrm{~Pa}$ and $2.10^{-25} \mathrm{~Pa}$ respectively. This allows neglecting the ratio $\mathrm{P}_{\mathrm{O}_{2}, \mathrm{Eq}} / \mathrm{P}_{\mathrm{O}_{2}}$ compared to 1 , and thus we obtain:

$\phi_{1}=k_{1}\left(\frac{K_{4}^{2} K_{5}^{2} K_{2}}{1+K_{4}^{2} K_{5}^{2} K_{2}}\right)^{2} P_{O_{2}}$

Appendix B. Calculation of the external surface area of a copper particle along its oxidation reaction. 
Notations:

$V_{\mathrm{Cu}_{2} \mathrm{O}} \quad$ the volume of the cuprous oxide $\left(\mathrm{m}^{3}\right)$

$V_{m, \mathrm{Cu}_{2} \mathrm{O}} \quad$ the molar volume of the cuprous oxide $\left(\mathrm{m}^{3} \cdot \mathrm{mol}^{-1}\right)$

$n_{0, C u} \quad$ the initial copper amount in a copper grain (mol)

$v_{\mathrm{Cu}_{2} \mathrm{O}} \quad$ the algebraic stoichiometric number of the cuprous oxide in overall reaction (R1)

$r_{0} \quad$ the initial radius of the copper particle $(\mathrm{m})$

$r_{e} \quad$ the external radius of the copper particle along the reaction (m)

Calculation of $s_{\text {ext }}(\tau, t)$

The extent of conversion of a copper particle during oxidation reaction is given by:

$\alpha=\left(\frac{V_{\mathrm{Cu}_{2} \mathrm{O}}}{v_{\mathrm{Cu}_{2} \mathrm{O}} \cdot V_{m, C u_{2} \mathrm{O}} \cdot n_{0, \mathrm{Cu}}}\right)$

The volume of the cuprous oxide produced by the oxidation of a spherical particle is given by:

$V_{\mathrm{Cu}_{2} \mathrm{O}}=4 / 3 \pi\left(r_{e}^{3}-r_{0}^{3}\right)$

By derivation of Eq. (A.2.1) and Eq. (A.2.2) we obtain the following reaction rate expression:

$\frac{d \alpha}{d t}=\frac{4 \pi r_{e}^{2}}{n_{0, C u} v_{\mathrm{Cu}_{2} \mathrm{O}} V_{m, \mathrm{Cu}_{2} \mathrm{O}}} \frac{d r_{e}}{d t}$

Moreover, the " $\phi S_{m}$ " test has shown that, before the slowdown of the reaction, rate could be written as:

$\frac{d \alpha}{d t}=\phi s_{m}(t)$ 
Taking into account that the rate determining step occurs at the external surface of the particle (adsorption step), $s_{m}(t)$ is given for a unique particle by:

$$
s_{m}(t)=\frac{s_{e x t}(t)}{n_{0, C u}}=\frac{4 \pi r_{e}^{2}}{n_{0, C u}}
$$

Combining the tow Eqs (A.2.4) and (A.2.5) we obtain:

$$
\frac{d \alpha}{d t}=\phi \frac{4 \pi r_{e}^{2}}{n_{0, C u}}
$$

The integration of Eqs (A.2.3) and (A.2.6) between $\tau$ (the time in which the nucleus appeared) and $t$ leads to the expression of the external radius of the particle:

$$
r_{e}=r_{0}\left(1+\frac{\phi v_{\mathrm{Cu}_{2} \mathrm{O}} V_{m, \mathrm{Cu}_{2} \mathrm{O}}}{r_{0}}(t-\tau)\right)
$$

Since $\mathrm{z}=\mathrm{V}_{\mathrm{m}, \mathrm{Cu}_{2} \mathrm{O}} / 2 \mathrm{~V}_{\mathrm{m}, \mathrm{Cu}}$ :

$$
r_{e}=r_{0}\left(1+\frac{\phi z V_{m, C u}}{r_{0}}(t-\tau)\right)
$$

And thus:

$$
s_{e x t}(\tau, t)=4 \pi r_{0}^{2}\left(1+\frac{\phi z V_{m, C u}}{r_{0}}(t-\tau)\right)^{2}
$$




\section{Supplementary materials}
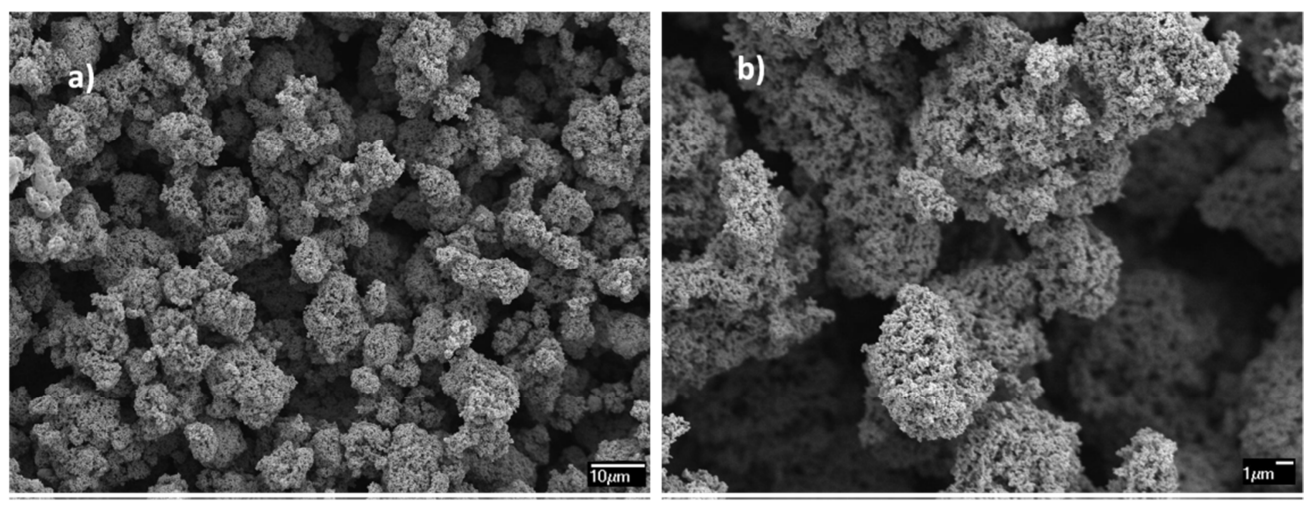

Fig S1: SEM images of copper powder after the reductive treatment (a) x1000; (b) x3300.

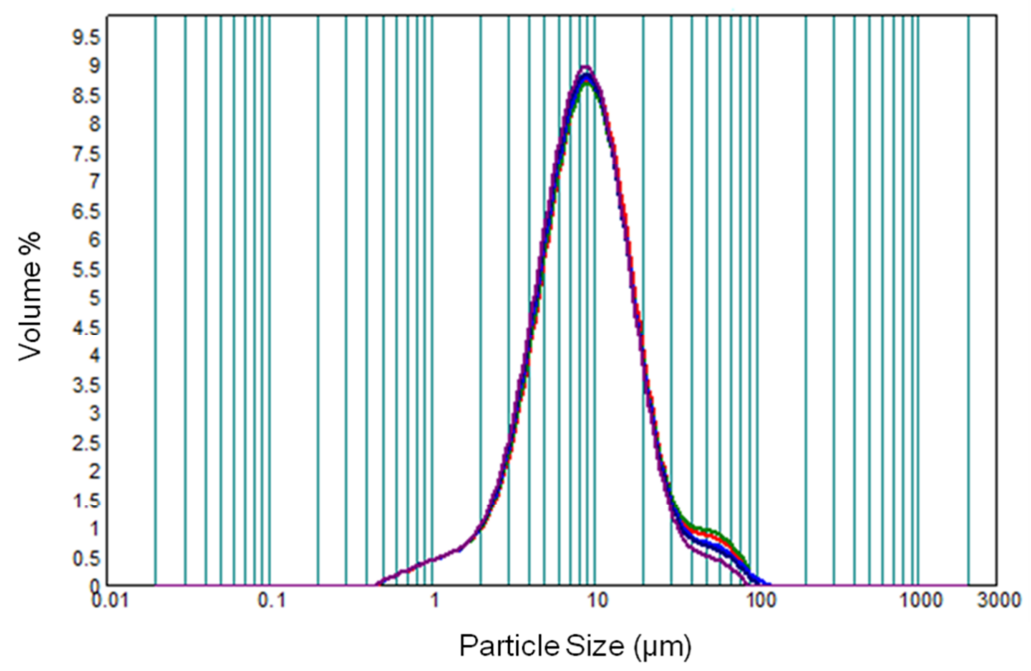

Fig S2: Particle size distribution of the agglomerates. 